\title{
Quality of pediatric clinical practice guidelines
}

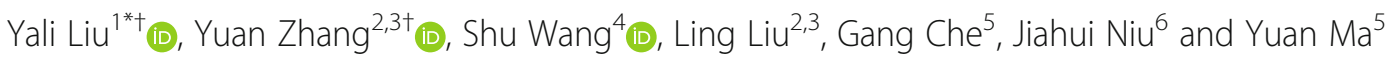

\begin{abstract}
Background: There is a lack of a comprehensive evaluation for pediatric clinical practice guidelines (CPGS) published in recent years. Here, we assessed the quality of pediatric CPGs, considering factors that might affect their quality. The aim of the study is to promote a more coherent development and application of CPGs.

Methods: Pediatric CPGs published in PubMed, MedLive, Guidelines International Network, National Institute for Health and Care Excellence, and World Health Organization between 2017 and 2019 were searched and collected. Paired researchers conducted screening, data extraction, and quality assessment using the Appraisal of Guidelines for Research and Evaluation II (AGREE II). Linear regression analysis determined the factors affecting CPGs' quality.

Results: The study included a total of 216 CPGs, which achieved a mean score of 4.26 out of 7 points (60.86\%) in the AGREE II assessment. Only 6.48\% of the CPGs reached the "recommend" level. The remaining $69.91 \%$ should have been modified before recommendation, while the other $23.61 \%$ did not reach the recommended level at all. The overall quality of recent pediatric CPGs was higher than previously, and the proportion of CPGs with lowquality decreased over time. However, there were still too few CPGs that reached a high-quality level. The "applicability" and "rigor of development" domains had generally low scores. CPGs formulated by developing countries or regions, those that are not under an organizations or groups responsibility, and those that used nonevidence-based methods were found to be associated with poorer quality in different domains as independent or combinational factors.
\end{abstract}

Conclusions: The quality of pediatric CPGs still needs to be improved. Specifically, a quality control before applying new CPGs should be essential to ensure their quality and applicability.

Keywords: Quality, Pediatric, Clinical practice guidelines, Evidence-based medicine

\section{Background}

Clinical practice guidelines (CPGs) are statements to guide health providers and patients [1]. High-quality and rigorously-developed CPGs with appropriate recommendations improve clinical and public health outcomes by helping health providers follow the right clinical practice $[2,3]$. Furthermore, policymakers and educators can

\footnotetext{
* Correspondence: |yl_201006@126.com

${ }^{+}$Yali Liu and Yuan Zhang contributed equally as co-first authors. ${ }^{1}$ Center for Clinical Epidemiology and Evidence-based Medicine, Beijing Children's Hospital, Capital Medical University, National Center for Children's Health, No. 56 Nanlishi Road, Xicheng District, Beijing 100045, China Full list of author information is available at the end of the article
}

establish more appropriate health policies and enhance appraisal skills in education with the help of CPGs $[4,5]$. However, implementation of CPGs with insufficient quality or inappropriate contents may mislead clinicians $[6,7]$. Therefore, it is essential to develop CPGs with better quality and appropriate content. When implementing CPGs in everyday clinical practice, users should pay attention to the content and local adaptations of the guidelines and their quality $[8,9]$.

The Appraisal of Guidelines for Research and Evaluation (AGREE) instrument was first proposed in 2003 to verify the quality of CPGs by the AGREE collaboration [10]. After that, the updated AGREE II [11] and a

(c) The Author(s). 2021 Open Access This article is licensed under a Creative Commons Attribution 4.0 International License, which permits use, sharing, adaptation, distribution and reproduction in any medium or format, as long as you give appropriate credit to the original author(s) and the source, provide a link to the Creative Commons licence, and indicate if changes were made. The images or other third party material in this article are included in the article's Creative Commons licence, unless indicated otherwise in a credit line to the material. If material is not included in the article's Creative Commons licence and your intended use is not permitted by statutory regulation or exceeds the permitted use, you will need to obtain permission directly from the copyright holder. To view a copy of this licence, visit http://creativecommons.org/licenses/by/4.0/ The Creative Commons Public Domain Dedication waiver (http://creativecommons.org/publicdomain/zero/1.0/) applies to the data made available in this article, unless otherwise stated in a credit line to the data. 
checklist, Reporting Items for Practice Guidelines in Healthcare (RIGHT) [12], were released. Although AGREE II has several limitations, especially related to the assessment of CPGs content [13-15], it is still a helpful and widely recognized tool for assessing CPG quality [16, 17]. AGREE II can also provide a methodological strategy in CPG development, which is very useful for CPG developers, health care providers, policymakers, and educators [18]. So far, it has been widely used and recognized in the quality assessment of CPGs $[16,17]$.

Recently, the number of pediatric CPGs grew substantially. However, some reports raised concerns about their quality $[19,20]$. Previous quality assessments of pediatric CPGs are out of date [21, 22] or only focus on a certain field [23, 24]. A comprehensive and up-to-date evaluation of the quality of pediatric CPGs published in recent years is lacking [25-27]. Therefore, the present study aimed to systematically search pediatric CPGs published between 2017 and 2019, assess their quality, and explore the factors that might influence them.

\section{Methods \\ Eligibility criteria}

To be included in the study, CPGs had to be either clinical practice guidelines, clinical treatment guidelines, or clinical recommendations focused on the pediatric population, defined as under 18 years old or a subset of it. All included CPGs should be in English to represent internationally recognized CPGs. The present study aimed to evaluate recent CPGs; therefore, we only included pediatric CPGs published between 2017 and 2019. We excluded documents that were not original CPGs (i.e., literature reviews, position papers, letters; paraphrase, interpretation, or analysis of previous CPGs). We included only the newest revised version of CPG updates published between 2017 and 2019, to prevent multiple counting.

\section{Search strategy}

The following search engines and databases were systematically searched, PubMed (pubmed.gov), MedLive (guide.medlive.cn), Guidelines International Network (GIN; g-i-n.net), National Institute for Health and Care Excellence (NICE; nice.org.uk), and World Health Organization (WHO; who.int). The language limit was set as "English" and the published time limit was "from January 1, 2017, to December 31, 2019". The searching terms included pediatric restriction, "Child $(M$, for Mesh)" or "Child, Preschool (M)" or "Infant (M)" or "Adolescent (M)" or "Infant, Newborn (M)" or "Child" (* for wildcard)" or "pediat"” or "paediat" or" "infan" or "youth" or "toddler" or "adolesc" or "teen" or "boy" or "girl" or" "bab" or "preschool"" or "pre-school"; and guideline restriction, "Practice Guideline (Publication Type) or "Guideline" or" "Guidance*" or "Recommendation" or "Consensus*."

\section{Guideline selection and data extraction}

The CPG selection and data extraction procedures were accomplished by two researchers independently. After cross-checking the selected CPGs and extracting data, the two researchers reached a consensus. In case disagreements occurred, an experienced senior reviewer was consulted and made the final decision.

After summarizing the records from all databases, we ran a software-assisted (Endnote; Clarivate Analytics, MA., USA, version 20) [28] duplication process on the data set, followed by a two-step selection procedure. The first step was to select CPGs that potentially met the eligibility criteria by screening titles and abstracts. After that, a full-text analysis determines the CPGs to include in the final data set. To prevent omissions, a group of researchers was arranged to search for CPGs from references and citations of previously included CPGs. Figure 1 shows the systematic searching and selection procedure.

The data extraction procedure collected the following parameters: published year, country or region of origin (divided into developing and developed countries or regions according to the list of World Trade Organization (WTO), version 2019), organization or group responsible for CPG development (individual, few persons, or small teams were excluded), applied population, and field of focus (based on the International Classification of Diseases 11th Revision, ICD-11; released by WHO on June 18, 2018). After reviewing the full text, the reviewers also assessed whether the methodology and CPGs were evidence-based or not. The evidence-based CPGs were defined by the Health and Medicine Division of the American National Academies as "statements that include recommendations intended to optimize patient care and are informed by a systematic review of evidence and an assessment of the benefits and harms of alternative care options" [29]. Evidence-based CPGs needed to be based on summarizing and analyzing existing evidence. The other CPGs that lacked evidence-base (e.g., based on expert opinion only) were considered as nonevidence-based CPGs.

\section{Quality assessment}

The quality of the included CPGs was appraised by two reviewers using the AGREE II instrument [18]. The reviewers were pediatricians who had extensive clinical pediatrics and evidence-based medicine experience. Before the appraisals, the reviewers completed AGREE II online tutorial training (agreetrust.org) and practiced under the supervision of a senior experienced reviewer. 


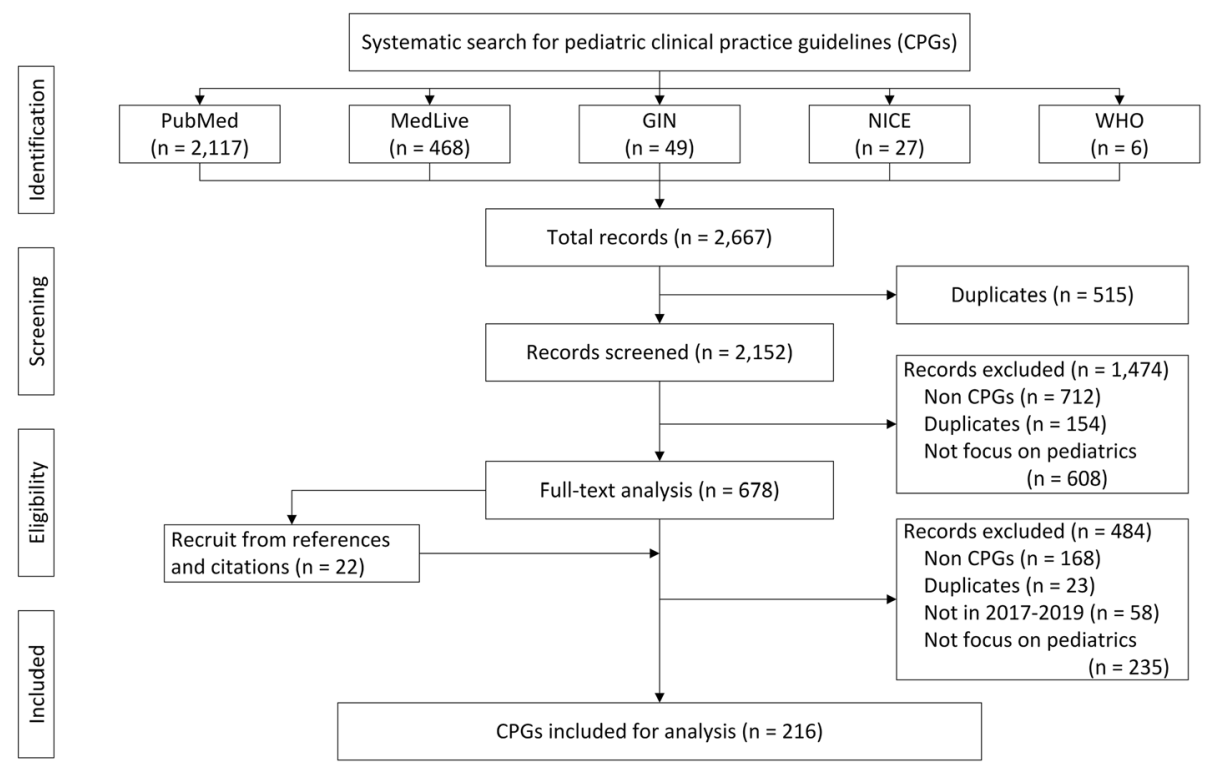

Fig. 1 Flow diagram of the systematic searching and selecting for pediatric clinical practice guidelines (CPGs) procedure. CPGs: Clinical practice guidelines; GIN: Guidelines International Network; NICE: National Institute for Health and Care Excellence; WHO: World Health Organization

A multi-round test assessment was required for the two reviewers. In the first round, each reviewer was required to independently assess ten randomly selected CPGs. The scores assigned by these two reviewers in each item were tested for consistency by the Intraclass Correlation Coefficient (ICC). For items that achieved ICC values less than 0.85 , the reviewers needed to review the AGREE II instrument and discussed the discrepancy to reach a consensus. After that, another test assessment was conducted in the second round. The assessment was considered complete after we finished at least threeround tests and achieved an ICC value no less than 0.85 in each item.

The AGREE II consists of 23 key items in 6 domains to capture different dimensions of CPG quality, which include scope and purpose (items 1-3), stakeholder involvement (items 4-6), rigor of development (items 714), clarity of presentation (items 15-17), applicability (18-21), and editorial independence (items 22-23) [11, 18]. Each item is assigned a score from 1 (strongly disagree, when no given information is relevant) to 7 (strongly agree, when full criteria of the item are met). The more criteria that are met, the higher the scores are given. According to the AGREE II instrument, scores of each domain are calculated as follows: the difference between maximum possible score and minimum possible score divided by the difference between actually obtained score and minimum possible score. Furthermore, according to the instrument, the reviewers provided two overall assessments of the CPG based on the six domains' quality. The reviewers assigned an overall quality score from 1 to 7 (higher scores indicating higher quality) by taking into account the total scores from each of the six domains as well as personal judgement made by the reviewers. If the overall assessment scores given by these two reviewers differed by 1 point, the lower score was assigned; if it varied by 2 points, the average scores were assigned; and if it differed by $\geq 3$ points, the reviewers reviewed for agreement [17]. To reach the recommended level, CPGs had to achieved overall assessment scores of 6 and 7 (above $80 \%$ of 7 scores). With an overall score of 4 and 5 (60 to $80 \%$ of 7 scores) the level was "recommended with modification", while CPGs with a score of 1 to 3 (less than $60 \%$ of 7 scores) were not recommend [19, 30,31]. Taking into account the criteria considered in the assessment process, if the CPG had serious issues in one of the domains, it would be downgraded one level $[17,31]$.

To ensure the validity and reliability of the assessment, after the overall assessment procedure, 10\% of the assessments were randomly selected by a senior experienced reviewer and re-assessed. The samples were divided with simple random sampling, and the random number table was generated by the SPSS software pack (IBM, NY, USA; version 26). Additionally, the overall quality scores of CPGs in different fields, organizations, groups, countries, or regions were summarized and ranked. Only variables with at least 3 CPGs were given a ranking. The ranking was based on the mean overall assessment scores.

\section{Statistical analysis}

Continuous variables (e.g., AGREE II scores) were presented as mean; categorical variables (e.g., recommendation 
levels) were reported as a number and a percentage. The comparison of categorical variables was conducted by Pearson's $x^{2}$ test or Fisher's exact test as appropriate. The two groups' continuous variables were compared using a twosample $t$-test or Mann-Whitney signed-rank test determined by data distribution and variance homogeneity. The Kolmogorov-Smirnov test was used as a normal distribution test. Leneve's test was conducted to explore the homogeneity of variance. The association between appraised scores and the characteristics of CPGs was analyzed by the linear regression to explore potential influential factors of CPGs' quality. The independent variables were set as country or region development (developing or developed), organization or group responsible (yes or no), and evidence-based method (yes or no). A $p$-value $<0.05$ was considered significant. All statistical analyses were performed with SPSS software pack (IBM, NY, USA; version 26).

\section{Results}

\section{Guideline selection and characteristics}

Overall, the search identified 2667 records, and 515 records were deleted in the software-assisted duplicates elimination process [28]. In the screening process, 1474 records were excluded (712 records were not CPGs, 154 records were duplicates, and 608 records did not focus on pediatrics). After including 22 records from references and citations and after excluding 484 records (168 records were not CPGs, 23 records were duplicates, 58 records did not publish in 2017 to 2019, and 235 records did not focus on pediatrics) in the full-text analysis, a total of 216 pediatric CPGs were used. Detailed selection procedures are shown in Fig. 1.

Among these CPGs, $71.3 \%$ were compiled by developed countries or regions; $85.65 \%$ of them were through organizations or groups. Three-quarters of included CPGs used evidence-based methods to develop CPGs, while the other one quarter did not. Table 1 . shows the characteristics of included pediatric CPGs.

\section{Quality assessment}

The included CPGs achieved a mean score of 4.26 out of 7 points (60.86\%) in the overall AGREE II assessment. Only $6.48 \%$ of the CPGs reached the "recommend" level, 69.91\% needed modifications before reaching the "recommend" level, and the other 23.61\% CPGs were not recommended. In the six domains assessment, the "clarity of presentation" domain achieved the highest mean score of $66.77 \%$. The "applicability" domain had the poorest mean quality, only achieving a mean score of $21.26 \%$. CPGs compiled by developed countries or regions and under organizations or groups achieved higher scores in different domains. Evidence-based CPGs achieved a significantly higher score lead in nearly all domains, overall assessment
Table 1 Characteristics of included pediatric clinical practice guidelines $(n=216)$

\begin{tabular}{|c|c|c|}
\hline Subject & $\mathrm{n}$ & $\%$ \\
\hline \multicolumn{3}{|l|}{ Country/ Region } \\
\hline Developed & 154 & 71.30 \\
\hline Developing & 62 & 28.70 \\
\hline \multicolumn{3}{|l|}{ Organization/ Group } \\
\hline Yes & 185 & 85.65 \\
\hline No & 31 & 14.35 \\
\hline \multicolumn{3}{|l|}{ Evidence based } \\
\hline Yes & 162 & 75.00 \\
\hline No & 54 & 25.00 \\
\hline \multicolumn{3}{|l|}{ Field (ICD-11 code) } \\
\hline 1 Infectious & 5 & 2.31 \\
\hline 2 Neoplasms & 16 & 7.41 \\
\hline 3 Blood & 3 & 1.39 \\
\hline 4 Immune & 4 & 1.85 \\
\hline 5 Endocrine & 36 & 16.67 \\
\hline 6 Mental & 14 & 6.48 \\
\hline 7 Sleep & 1 & 0.46 \\
\hline 8 Nervous & 12 & 5.56 \\
\hline 9 Visual & 1 & 0.46 \\
\hline 10 Ear & 6 & 2.78 \\
\hline 11 Circulatory & 7 & 3.24 \\
\hline 12 Respiratory & 11 & 5.09 \\
\hline 13 Digestive & 10 & 4.63 \\
\hline 14 Skin & 1 & 0.46 \\
\hline 15 Musculoskeletal & 11 & 5.09 \\
\hline 16 Genitourinary & 12 & 5.56 \\
\hline 17 Sexual & 3 & 1.39 \\
\hline 19 Perinatal & 33 & 15.28 \\
\hline 20 Developmental & 7 & 3.24 \\
\hline 21 Symptoms & 6 & 2.78 \\
\hline 22 External & 1 & 0.46 \\
\hline - a General & 16 & 7.41 \\
\hline
\end{tabular}

${ }^{\mathrm{a} G e n e r a l ~ f i e l d s ~(e . g ., ~ s c r e e n i n g ~ a n d ~ d i a g n o s i s) ~}$

scores $(p<0.001)$, and recommendation levels $(p<0.001)$ compared to non-evidenced CPGs. The score of overall CPGs and subgroups are presented in Table 2. The scores in each domain of different recommendation levels are summarized in Fig. 2. The CPGs that achieved lower recommendation levels were insufficient in "applicability" and "rigor of development".

Additionally, the score of CPGs in different fields (Supplemental Table 1.), organizations or groups (Supplemental Table 2.), and countries or regions (Supplemental Table 3.) were summarized and ranked. The CPGs related to the circulatory system, digestive system, 


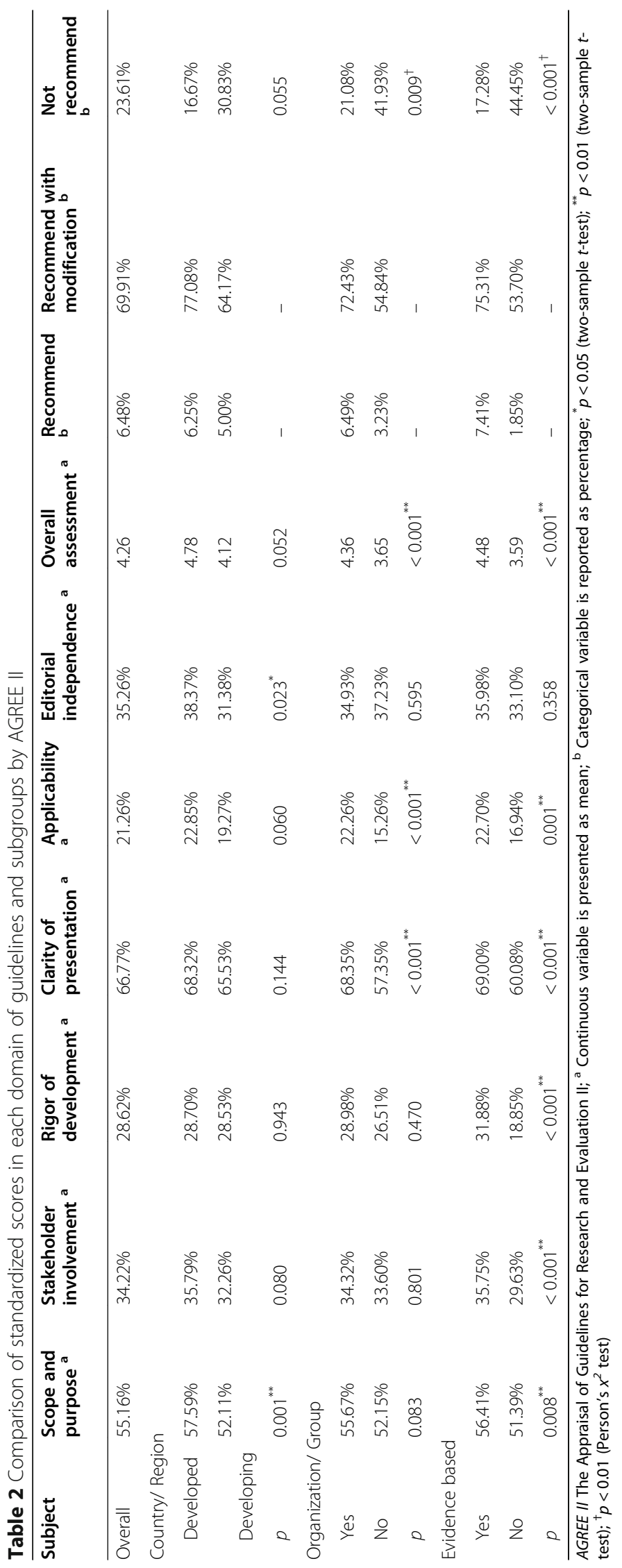




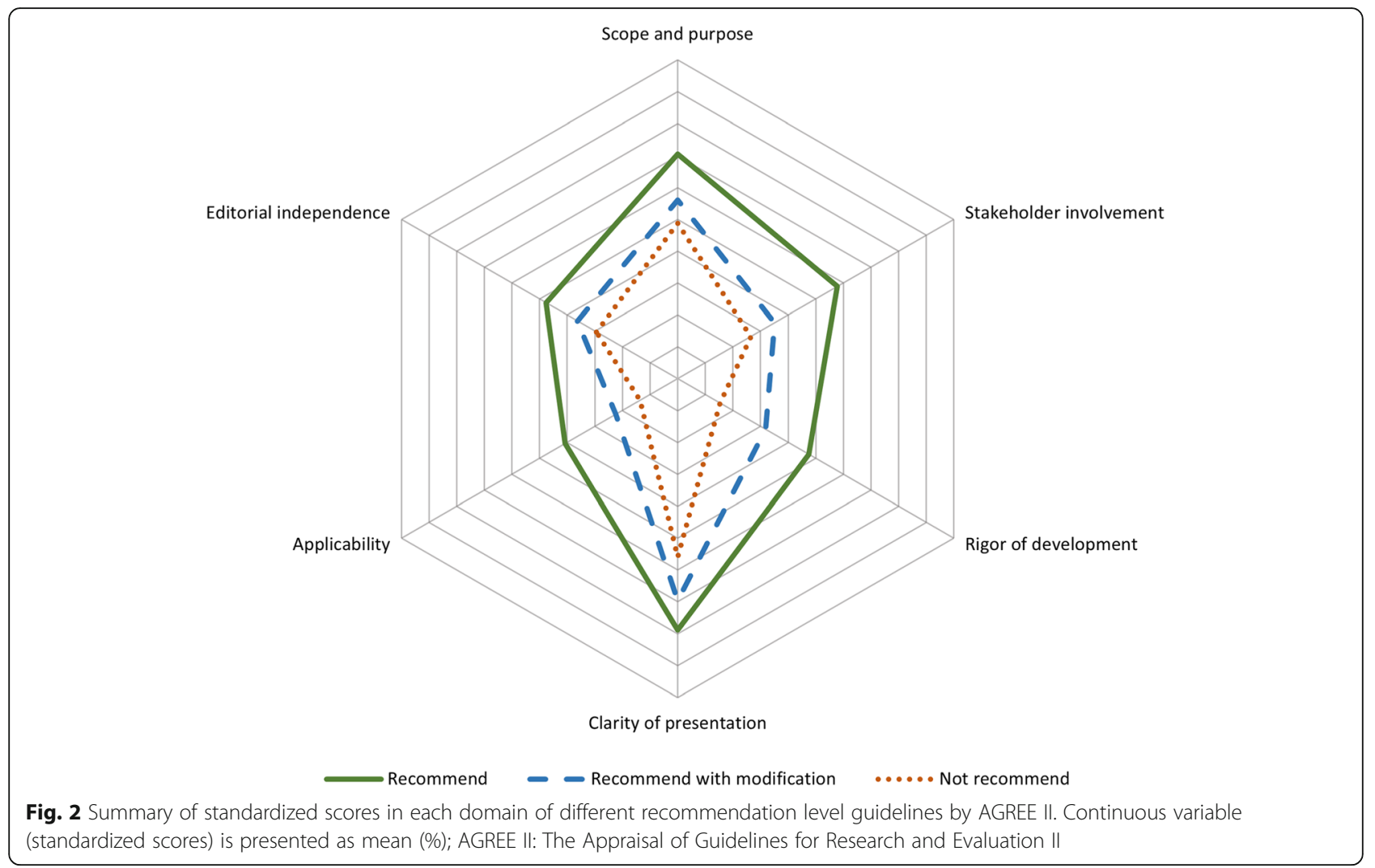

and general fields (e.g., screening and diagnosis) achieved higher overall assessment scores. The CPGs developed under the WHO, Queensland Health $(\mathrm{QH})$, and the American Academy of Pediatrics (AAP) responsibility had the highest quality. For different countries or regions' comparisons, CPGs developed by the U.K., Australia, and Italy had better quality.

\section{Influential factors}

The multi-factor linear regression was used to explore the association between scores in each domain and the characteristics of CPGs. After analysis, CPGs which were not organization or group responsible $(\beta=-0.179 ; 95 \% \mathrm{CI}=$ $-1.017,-0.175 ; p=0.006)$ and those that used a nonevidence-based method $(\beta=-0.312 ; 95 \% \mathrm{CI}=-1.180$, $0.498 ; p<0.001)$ were associated with poorer overall quality. Furthermore, CPGs formulated by developing countries or regions, those that are not under an organizations or groups responsibility, and those that used nonevidence-based methods were found to be associated with poorer quality in different domains as independent or combinational factors, as shown in Table 3.

\section{Discussion}

\section{Overall guideline quality}

Previous studies assessing quality assessment of pediatric CPGs are outdated or only focused on a specific field
[21-24]. Isaac et al. conducted a study in 2011 to evaluate the quality of development and reporting of 28 CPGs developed or endorsed by AAP. After assessment with AGREE II, they showed that the CPGs achieved an overall mean score of $55 \%$, which is lower than the present study. Furthermore, they reported 29\% of the CPGs with an overall score of $<50 \%$, while this proportion decreased in the present study [21]. These results suggest that the overall quality of pediatric CPGs improved since 2011. However, the number of CPGs reaching high quality (receiving the "recommend" level) did not change significantly, compared with before [21]. Xie et al. appraised pediatric CPGs related to communityacquired pneumonia published from January 2000 to March 2015. In their study, 30\% of CPGs achieved the "recommended" levels, 40\% of CPGs were "recommended with modifications", and 30\% of CPGs were "not recommended" [32]. Generally, based on existing research, the overall quality of pediatric CPGs improved compared to early CPGs [21, 32]. However, there were still few CPGs that reached a high-quality level. Moreover, the overall quality score was still inadequately compared to the quality evaluation for other recent CPGs focused on adults. Most of the studies that focused on adult CPGs reported a mean overall AGREE II scores of 4.77-5.97 in 7 points (68.21-85.35\%), and 8.2$50.0 \%$ of them could reach the "recommend" level [33- 
Table 3 Association of standardized scores in each domain by AGREE II and characteristics of guidelines using linear regression

\begin{tabular}{|c|c|c|c|c|c|}
\hline Domain and subject & $R^{2}$ & Adjusted $R^{2}$ & $\beta$ & $95 \% \mathrm{Cl}$ & $p$ \\
\hline Scope and purpose & 0.101 & 0.089 & & & \\
\hline Constant & & & - & $0.573,0.620$ & $<0.001^{* *}$ \\
\hline Country/ Region & & & -0.251 & $-0.092,-0.029$ & $<0.001^{* *}$ \\
\hline Organization/ Group & & & -0.096 & $-0.077,0.011$ & 0.144 \\
\hline Evidence based & & & -0.191 & $-0.089,-0.017$ & $0.004^{* *}$ \\
\hline Stakeholder involvement & 0.051 & 0.038 & & & \\
\hline Constant & & & - & $0.347,0.406$ & $<0.001^{* *}$ \\
\hline Country/ Region & & & -0.136 & $-0.079,-0.001$ & $0.044^{*}$ \\
\hline Organization/ Group & & & -0.002 & $-0.057,0.055$ & 0.972 \\
\hline Evidence based & & & -0.192 & $-0.110,-0.020$ & $0.005^{* *}$ \\
\hline Rigor of development & 0.106 & 0.093 & & & \\
\hline Constant & & & - & $0.290,0.360$ & $<0.001^{* *}$ \\
\hline Country/ Region & & & -0.034 & $-0.057,0.033$ & 0.608 \\
\hline Organization/ Group & & & -0.010 & $-0.069,0.060$ & 0.881 \\
\hline Evidence based & & & -0.325 & $-0.183,-0.079$ & $<0.001^{* *}$ \\
\hline Clarity of presentation & 0.141 & 0.129 & & & \\
\hline Constant & & & - & $0.666,0.720$ & $<0.001^{* *}$ \\
\hline Country/ Region & & & 0.061 & $-0.018,0.052$ & 0.341 \\
\hline Organization/ Group & & & -0.242 & $-0.146,-0.046$ & $<0.001^{* *}$ \\
\hline Evidence based & & & -0.242 & $-0.118,-0.037$ & $<0.001^{* *}$ \\
\hline Applicability & 0.081 & 0.068 & & & \\
\hline Constant & & & - & $0.227,0.283$ & $<0.001^{* *}$ \\
\hline Country/ Region & & & -0.156 & $-0.080,-0.007$ & $0.020^{*}$ \\
\hline Organization/ Group & & & -0.167 & $-0.118,-0.014$ & $0.013^{*}$ \\
\hline Evidence based & & & -0.172 & $-0.097,-0.013$ & $0.013^{*}$ \\
\hline Editorial independence & 0.031 & 0.017 & & & \\
\hline Constant & & & - & $0.345,0.437$ & $<0.001^{* *}$ \\
\hline Country/ Region & & & -0.160 & $-0.131,-0.012$ & $0.019^{*}$ \\
\hline Organization/ Group & & & 0.034 & $-0.064,0.107$ & 0.618 \\
\hline Evidence based & & & -0.074 & $-0.107,0.031$ & 0.278 \\
\hline Overall assessment & 0.142 & 0.130 & & & \\
\hline Constant & & & - & $4.386,4.838$ & $<0.001^{* *}$ \\
\hline Country/ Region & & & -0.055 & $-0.425,0.166$ & 0.389 \\
\hline Organization/ Group & & & -0.179 & $-1.017,-0.175$ & $0.006^{* *}$ \\
\hline Evidence based & & & -0.312 & $-1.180,-0.498$ & $<0.001^{* *}$ \\
\hline
\end{tabular}

AGREE II The Appraisal of Guidelines for Research and Evaluation II; ${ }^{*} p<0.05$ (linear regression); ${ }^{*} p<0.01$ (linear regression)

35]. A study published in 2018 analyzed 89 CPGs on adult critical care, and reported a mean overall score of $83 \%$, which was higher than this review [36]. The study by Madera et al. suggested that $50 \%$ of the eight adult CPGs on screening and diagnosis of oral cancer were assessed as "recommend" and the other 50\% were assigned as "recommended with modifications" [37]. Compared with CPGs for adults, the quality of pediatric CPGs still needs to be improved.

\section{Quality of domains}

Compared with other studies using the AGREE II assessment, the present study also revealed that "applicability" and "rigor of development" domains had poorer quality [21, 22, 35, 36]. A study of previous assessment of pediatric CPGs showed that "applicability", "editorial independence", and "stakeholder involvement" domains achieved the lowest mean scores, at 19, 40, and $42 \%$, respectively [22]. We also compared the scores of each 
domain among CPGs with different recommendation levels to determine which domains affect the recommendation level. As shown in Fig. 2, the CPGs that achieved lower recommendation levels were insufficient in "applicability" and "rigor of development", which indicated these domains affected the overall quality of pediatric CPGs.

The "applicability" domain mainly focuses on the barriers and facilitators to apply the CPG [18]. This domain required CPGs to consider facilitators and barriers in the application, and provide advice or tools for different age groups and regions. The clinical manifestations, progress, and outcomes of pediatric diseases are different from those of adult diseases. Therefore, before applying a CPG, it is necessary to evaluate its quality and scope of application. The study of Boluyt et al. was a great example of adopting CPGs [22]. They conducted a systematic review of CPGs and assessed the quality and applicability of the CPGs. Furthermore, they synthesized the expert opinions to determine the CPGs that can be used in local clinical practice [22].

The "rigor of development" domain is the key to the development of a qualified CPG. This domain relates to gathering and synthesizing the evidence, promoting recommendations and update schedules of CPGs [18]. The AGREE II manual [11] and RIGHT checklist [12] provide various suggestions in CPG development and reporting, such as systematic methods, evidence criteria, review procedure, and update schedule, which should be consulted and followed in the proposal, development, report, review, and update procedures of a CPG.

Recently, several studies raised the concern that conflict of interest could affect the quality of CPGs [38-41]. However, only limited CPGs described the management of financial conflicts of interest [40]. Komesaroff et al. proposed the concept of "conflicts of interests" as "the condition that arises when two coexisting interests directly conflict with each other: that is when they are likely to compel contrary and incompatible outcomes" [39]; while Grundy et al. and Wiersma et al. suggested "nonfinancial conflicts of interests" should also receive awareness in health and medicine [41, 42]. The AGREE II provides a domain as "editorial independence" to evaluate whether the funding bodies have influenced the content and whether conflicts of interests of CPG development group members have been recorded and addressed [18]. Our study showed that the "editorial independence" domain achieved a mean score of only $35.26 \%$ for pediatric CPGs. In addition, several previous studies highlighted that "editorial independence" domain of AGREE II in pediatric CPGs had inappropriate quality (a mean score of 17-48\%) [19-21]. Thus, the potential conflicts of interests in CPG development should be disclosed and reviewed carefully. Independent committees should also be engaged for evaluation and management $[18,40]$.

\section{Influential factors of quality}

Some studies showed a significant improvement in CPGs' quality under organizations or groups' responsibility $[8,20]$. According to the study of Font-Gonzalez et al., CPGs under organizations or groups' responsibility were more likely to have high quality [20]. In the present study, only a few CPGs (14.3\%) were not conducted by organizations or groups. Reliable organizations or groups can complete the CPG development procedures, use appropriate methods, and report in a more complete manner, which might be relatively difficult for an individual or small team [20]. Furthermore, a small team might lack the skills or training in developing CPGs as compared with large organizations or groups [20].

Previous studies suggested that a non-evidence-based method in CPG development might significantly affect quality [43]. In the present study, one-quarter of CPGs did not use evidence-based methods, and we found that non-evidence-based methods had significant influence in nearly all domains. The evidence-based method was important in CPG development and clinical decisionmaking [44]. By using an evidence-based method, we could systematically search and summarize previous research, reducing the limitations and bias [45].

Several studies suggested CPGs developed in regions with different economic development statuses might influent the quality of CPGs $[22,43]$. The present study also found that CPGs developed by developing countries or regions had poorer quality in domains related to "scope and purpose", "stakeholder involvement", "applicability", and "editorial independence". Also, we found that most of the CPGs with poor quality developed by developing countries or regions did not follow a strict and comprehensive development procedure; and some of them did not use the evidenced-based method, which might influence quality. Most of the CPGs with high quality were developed by countries or organizations with significant funding and resource. A previous study suggested that AAP's internal CPGs had significantly higher total scores than endorsed CPGs [21]. These CPGs with high quality were developed under a strictly completed, evidence-based CPG development procedure. Additionally, the CPG committee consisted of clinical experts, methodologists, and others involved from different fields, improving the rigor in development and applicability in practice [46]. For resource-limited developing countries, it might be a challenge to form a complete expert group to complete the CPG development procedure. One possible way of these regions was adapting existing high-quality CPGs [47]. In addition, international collaboration could be an acceptable way 
of developing a CPG [48]. However, as there were nuances in many healthcare systems worldwide that might preclude the direct deployment of international CPGs, agencies should consider CPG adaptations for their institutions. The process for guideline adaptation (ADAP TE) could create CPG versions, derived from existing CPGs, but modified to local settings, which is a costeffective and less resource-intensive approach to CPG development [48]. Recently, Dizon et al. suggested a standardized procedure to adopt, adapt or contextualize recommendations from existing CPGs of good quality, promoting the use of scarce resources more focused on implementation [49]. These studies provided meaningful attempts at tailoring CPGs to the local context.

\section{Limitations}

The present study had several limitations. Firstly, because the present study's primary purpose was to evaluate the quality of recent pediatric CPGs, we only assessed CPGs published in the past 3 years, which limits the evaluation of the change in CPGs' quality over time. Also, only English CPGs were included in this study; therefore, further research should analyze CPGs that were written in different languages when possible. Secondly, the AGREE II assessment was related to the personal judgment of reviewers, which might introduce selection bias. Thus, we conducted strict training and test assessment procedures. A re-assessment procedure was also performed to reduce selection bias. Finally, AGREE II has its inherent limitations. AGREE-II scores are dependent upon reporting, while some CPG committees may comply with the requirements but do not ultimately report. In addition, AGREE II only focuses on the quality in developing and reporting procedures of CPGs, but the evidence behind the recommendations cannot be evaluated. Thus, AGREE II is not sufficient to ensure that CPG recommendations are appropriate and accurate [13-15]. Several studies suggested that a new version of AGREE with an evaluation of CPGs' contents should be proposed, which would require a great effort and collaboration [13-15]. We suggest health providers should closely follow new versions of well-developed tools for the appraisal of CPGs. Before that, health care providers should assess CPG quality using tools like AGREE II and evaluate CPG content and local adaptations before implying recommendations from a CPG $[26,50,51]$. Furthermore, different CPGs might contradict some recommendations, which cannot be solved by AGREE II alone. When these contradictions occur, health providers should review its contents and evidence. Thus, the decision to implement recommendations from CPGs requires careful considerations, including its quality, contents, adaptions, patients' wishes, resources, feasibility, and fairness.

\section{Conclusions}

In conclusion, the quality of the pediatric CPGs was rarely excellent. The overall quality of recent pediatric CPGs was higher than previous pediatric CPGs, and the proportion of CPGs with low quality decreased. However, there were still limited CPGs reaching a highquality level. The "applicability" and "rigor of development" domains had low quality. CPGs formulated by developing countries or regions, those that are not under an organizations or groups responsibility, and those that used non-evidence-based methods were found to be associated with poorer quality in different domains as independent or combinational factors.

The quality of pediatric CPGs still needs more research and improvement. It is necessary to strengthen the development and reporting procedures of pediatric CPGs. Besides that, the quality and applicability of a CPG should be evaluated before its application.

\section{Abbreviations \\ CPG: Clinical practice guideline; AGREE: Appraisal of Guidelines for Research and Evaluation; RIGHT: Reporting Items for Practice Guidelines in Healthcare; PRISMA: Preferred Reporting Items for Systematic Reviews and Meta-analyses; GIN: Guidelines International Network; NICE: National Institute for Health and Care Excellence; WHO: World Health Organization; ASRM: American Society for Reproductive Medicine; QH: Queensland Health; AAP: American Academy of Pediatrics}

\section{Supplementary Information}

The online version contains supplementary material available at https://doi. org/10.1186/s12887-021-02693-1.

Additional file 1: Supplemental Table 1. Comparison of standardized scores in each domain of guidelines in different fields (ICD-11 code) by AGREE II.

Additional file 2: Supplemental Table 2. Comparison of standardized scores in each domain of guidelines established by different organizations or groups by AGREE II.

Additional file 3: Supplemental Table 3. Comparison of standardized scores in each domain of guidelines established by different countries or regions by $A G R E E \|$.

\section{Acknowledgments}

Not applicable.

\begin{abstract}
Authors' contributions
Yali Liu conceptualized and designed the study, drafted the initial manuscript, coordinated, and supervised data collection, reviewed, and revised the manuscript. Yuan Zhang and Shu Wang designed the data collection instruments, collected data, carried out the initial analyses, drafted the initial manuscript, reviewed, and revised the manuscript. Ling Liu, Gang Che, Jiahui Niu, and Yuan Ma collected data, carried out the initial analyses, reviewed and revised the manuscript. All authors approved the final manuscript as submitted and agree to be accountable for all aspects of the work.
\end{abstract}

\section{Funding}

No funding was secured for this study.

Availability of data and materials

All data generated or analyzed during this study are included in this published article and its supplementary information files. 


\section{Declarations}

Ethics approval and consent to participate

Not applicable.

\section{Consent for publication}

Not applicable.

\section{Competing interests}

The authors declare that they have no competing interests.

\section{Author details}

${ }^{1}$ Center for Clinical Epidemiology and Evidence-based Medicine, Beijing Children's Hospital, Capital Medical University, National Center for Children's Health, No. 56 Nanlishi Road, Xicheng District, Beijing 100045, China. ${ }^{2}$ Dalian Medical University, Dalian 116044, Liaoning, China. ${ }^{3}$ Department of Pediatric Hematology-Oncology, Dalian Municipal Women and Children's Medical Center, Dalian 116037, Liaoning, China. ${ }^{4}$ Department of Neurosurgery, SanBo Brain Hospital, Capital Medical University, Beijing 100093, China. ${ }^{5}$ The First Hospital of Lanzhou University, Lanzhou 730000, Gansu, China. ${ }^{6}$ Capital Medical University, Beijing 100069, China.

\section{Received: 15 October 2020 Accepted: 22 April 2021}

Published online: 07 May 2021

\section{References}

1. Woolf SH, Grol R, Hutchinson A, Eccles M, Grimshaw J. Clinical guidelines: potential benefits, limitations, and harms of clinical guidelines. Bmj. 1999; 318(7182):527-30. https://doi.org/10.1136/bmj.318.7182.527.

2. Fiks AG, Ross ME, Mayne SL, Song L, Liu W, Steffes J, McCarn B, Grundmeier RW, Localio AR, Wasserman R. Preschool ADHD Diagnosis and Stimulant Use Before and After the 2011 AAP Practice Guideline. Pediatrics. 2016; 138(6):e20162025. https://doi.org/10.1542/peds.2016-2025. Epub 2016 Nov 15.

3. Djulbegovic B, Bennett $\mathrm{CL}$, Guyatt G. A unifying framework for improving health care. J Eval Clin Pract. 2019;25(3):358-62. https://doi.org/10.1111/ jep.13066.

4. Browman GP, Snider A, Ellis P. Negotiating for change. The healthcare manager as catalyst for evidence-based practice: changing the healthcare environment and sharing experience. Healthc Pap. 2003;3(3):10-22. https:// doi.org/10.12927/hcpap..17125.

5. Steinert Y, Mann K, Anderson B, Barnett BM, Centeno A, Naismith L, et al. A systematic review of faculty development initiatives designed to enhance teaching effectiveness: a 10-year update: BEME guide no. 40. Med Teach. 2016;38(8):769-86. https://doi.org/10.1080/0142159X.2016.1181851.

6. Kastner M, Bhattacharyya O, Hayden L, Makarski J, Estey E, Durocher L, et al. Guideline uptake is influenced by six implementability domains for creating and communicating guidelines: a realist review. J Clin Epidemiol. 2015;68(5): 498-509. https://doi.org/10.1016/j.jclinepi.2014.12.013.

7. Djulbegovic B, Bennett CL, Guyatt G. Failure to place evidence at the Centre of quality improvement remains a major barrier for advances in quality improvement. J Eval Clin Pract. 2019;25(3):369-72. https://doi.org/10.1111/ jep.13146.

8. Jolliffe L, Lannin NA, Cadilhac DA, Hoffmann T. Systematic review of clinical practice guidelines to identify recommendations for rehabilitation after stroke and other acquired brain injuries. BMJ Open. 2018;8(2):e018791. https://doi.org/10.1136/bmjopen-2017-018791.

9. Le JV. Implementation of evidence-based knowledge in general practice. Dan Med J. 2017:64(12):B5405.

10. AGREE-Collaboration. Development and validation of an international appraisal instrument for assessing the quality of clinical practice guidelines: the AGREE project. Qual Saf Health Care. 2003;12(1):18-23.

11. Brouwers MC, Kho ME, Browman GP, Burgers JS, Cluzeau F, Feder G, et al. AGREE II: advancing guideline development, reporting and evaluation in health care. Cmaj. 2010;182(18):E839-42. https://doi.org/1 0.1503/cmaj.090449.

12. Chen $Y$, Yang $K$, Marušic A, Qaseem A, Meerpohl JJ, Flottorp S, et al. A reporting tool for practice guidelines in health care: the RIGHT statement. Ann Intern Med. 2017;166(2):128-32. https://doi.org/10.7326/M16-1565.

13. Watine J, Friedberg B, Nagy E, Onody R, Oosterhuis W, Bunting PS, et al. Conflict between guideline methodologic quality and recommendation validity: a potential problem for practitioners. Clin Chem. 2006;52(1):65-72. https://doi.org/10.1373/clinchem.2005.056952.

14. Burgers JS. Guideline quality and guideline content: are they related? Clin Chem. 2006;52(1):3-4. https://doi.org/10.1373/clinchem.2005.059345.

15. Watine J. Is it time to develop AGREE III? CMAJ. 2019;191(43):E1198. https:// doi.org/10.1503/cmaj.73257.

16. Siering U, Eikermann M, Hausner E, Hoffmann-Eßer W, Neugebauer EA. Appraisal tools for clinical practice guidelines: a systematic review. PLoS One. 2013;8(12):e82915. https://doi.org/10.1371/journal.pone.0082 915.

17. Appenteng R, Nelp T, Abdelgadir J, Weledji N, Haglund M, Smith E, et al. A systematic review and quality analysis of pediatric traumatic brain injury clinical practice guidelines. PLoS One. 2018;13(8):e0201550. https://doi.org/1 0.1371/journal.pone.0201550.

18. The AGREE II Instrument [Electronic version] [http://www.agreetrust.org].

19. Chiappini E, Bortone B, Galli L, de Martino M. Guidelines for the symptomatic management of fever in children: systematic review of the literature and quality appraisal with AGREE II. BMJ Open. 2017;7(7):e015404. https://doi.org/10.1136/bmjopen-2016-015404.

20. Font-Gonzalez A, Mulder RL, Loeffen EA, Byrne J, van Dulmen-den Broeder $\mathrm{E}$, van den Heuvel-Eibrink MM, et al. Fertility preservation in children, adolescents, and young adults with cancer: quality of clinical practice guidelines and variations in recommendations. Cancer. 2016;122(14):221623. https://doi.org/10.1002/cncr.30047.

21. Isaac A, Saginur M, Hartling L, Robinson JL. Quality of reporting and evidence in American Academy of Pediatrics guidelines. Pediatrics. 2013; 131(4):732-8. https://doi.org/10.1542/peds.2012-2027.

22. Boluyt $N$, Lincke $C R$, Offringa M. Quality of evidence-based pediatric guidelines. Pediatrics. 2005;115(5):1378-91. https://doi.org/10.1542/peds.2 004-0575.

23. Bhatt M, Nahari A, Wang PW, Kearsley E, Falzone N, Chen S, et al. The quality of clinical practice guidelines for management of pediatric type 2 diabetes mellitus: a systematic review using the AGREE ॥ instrument. Syst Rev. 2018;7(1):193. https://doi.org/10.1186/s13643-0180843-1.

24. Olweny CN, Arnold P. Clinical practice guidelines in pediatric anesthesia: what constitutes high-quality guidance? Paediatr Anaesth. 2020;30(2):89-95. https://doi.org/10.1111/pan.13805.

25. Alonso-Coello P, Irfan A, Solà I, Gich I, Delgado-Noguera M, Rigau D, et al. The quality of clinical practice guidelines over the last two decades: a systematic review of guideline appraisal studies. Qual Saf Health Care. 2010; 19(6):e58. https://doi.org/10.1136/qshc.2010.042077.

26. Armstrong JJ, Goldfarb AM, Instrum RS, MacDermid JC. Improvement evident but still necessary in clinical practice guideline quality: a systematic review. J Clin Epidemiol. 2017;81:13-21. https://doi.org/10.1016/j.jclinepi.201 6.08.005.

27. Gagliardi AR, Brouwers MC. Do guidelines offer implementation advice to target users? A systematic review of guideline applicability. BMJ Open. 2015; 5(2):e007047. https://doi.org/10.1136/bmjopen-2014-007047.

28. The EndNote Team: EndNote. In., vol. EndNote 20. Philadelphia: Clarivate; 2013.

29. Institute-of-Medicine-(US)-Committee-on-Standards-for-DevelopingTrustworthy-Clinical-Practice-Guidelines. Clinical Practice Guidelines We Can Trust. Washington (DC): National Academies Press (US); 2011.

30. Holmer HK, Ogden LA, Burda BU, Norris SL. Quality of clinical practice guidelines for glycemic control in type 2 diabetes mellitus. PLoS One. 2013; 8(4):e58625. https://doi.org/10.1371/journal.pone.0058625.

31. Hoffmann-Eßer W, Siering U, Neugebauer EAM, Lampert U, Eikermann M. Systematic review of current guideline appraisals performed with the appraisal of guidelines for Research \& Evaluation II instrument-a third of AGREE II users apply a cut-off for guideline quality. J Clin Epidemiol. 2018; 95:120-7. https://doi.org/10.1016/j.jclinepi.2017.12.009.

32. Xie Z, Wang X, Sun L, Liu J, Guo Y, Xu B, et al. Appraisal of clinical practice guidelines on community-acquired pneumonia in children with AGREE II instrument. BMC Pediatr. 2016;16(1):119. https://doi.org/10.1186/s12887-0160651-5.

33. Kim JK, Chua ME, Ming JM, Santos JD, Zani-Ruttenstock E, Marson A, et al. A critical review of recent clinical practice guidelines on management of cryptorchidism. J Pediatr Surg. 2018;53(10):2041-7. https://doi.org/10.1016/j. jpedsurg.2017.11.050. 
34. Shen $W Q$, Yao L, Wang XQ, Hu Y, Bian ZX. Quality assessment of cancer cachexia clinical practice guidelines. Cancer Treat Rev. 2018;70:9-15. https:// doi.org/10.1016/j.ctrv.2018.07.008.

35. Tamás G, Abrantes C, Valadas A, Radics P, Albanese A, Tijssen MAJ, et al. Quality and reporting of guidelines on the diagnosis and management of dystonia. Eur J Neurol. 2018;25(2):275-83. https://doi.org/10.1111/ene.13488.

36. Chen Z, Hong Y, Liu N, Zhang Z. Quality of critical care clinical practice guidelines: assessment with AGREE II instrument. J Clin Anesth. 2018;51:407. https://doi.org/10.1016/j.jclinane.2018.08.011.

37. Madera M, Franco J, Solà I, Bonfill X, Alonso-Coello P. Screening and diagnosis of oral cancer: a critical quality appraisal of clinical guidelines. Clin Oral Investig. 2019;23(5):2215-26. https://doi.org/10.1007/s00784-018-2668-7.

38. Annane D, Lerolle N, Meuris S, Sibilla J, Olsen KM. Academic conflict of interest. Intensive Care Med. 2019;45(1):13-20. https://doi.org/10.1007/ s00134-018-5458-4.

39. Komesaroff PA, Kerridge I, Lipworth W. Conflicts of interest: new thinking, new processes. Intern Med J. 2019;49(5):574-7. https://doi.org/10.1111/ imj.14233.

40. Elder K, Turner KA, Cosgrove L, Lexchin J, Shnier A, Moore A, et al. Reporting of financial conflicts of interest by Canadian clinical practice guideline producers: a descriptive study. Cmaj. 2020;192(23):E617-e625. https://doi. org/10.1503/cmaj.191737.

41. Grundy Q, Mayes C, Holloway K, Mazzarello S, Thombs BD, Bero L. Conflict of interest as ethical shorthand: understanding the range and nature of "non-financial conflict of interest" in biomedicine. J Clin Epidemiol. 2020;120: 1-7. https://doi.org/10.1016/j.jclinepi.2019.12.014.

42. Wiersma M, Kerridge I, Lipworth W. Dangers of neglecting non-financial conflicts of interest in health and medicine. J Med Ethics. 2018;44(5):319-22. https://doi.org/10.1136/medethics-2017-104530.

43. Chen Y, Wang C, Shang H, Yang K, Norris SL. Clinical practice guidelines in China. Bmj. 2018;360:j5158.

44. Horwitz RI, Hayes-Conroy A, Caricchio R, Singer BH. From evidence based medicine to medicine based evidence. Am J Med. 2017;130(11):1246-50. https://doi.org/10.1016/j.amjmed.2017.06.012.

45. Djulbegovic B, Guyatt GH. Progress in evidence-based medicine: a quarter century on. Lancet. 2017;390(10092):415-23. https://doi.org/10.1016/S01406736(16)31592-6.

46. Hirsh J, Guyatt G. Clinical experts or methodologists to write clinical guidelines? Lancet. 2009;374(9686):273-5. https://doi.org/10.1016/50140-673 6(09)60787-X.

47. Fervers B, Burgers JS, Voellinger R, Brouwers M, Browman GP, Graham ID, et al. Guideline adaptation: an approach to enhance efficiency in guideline development and improve utilisation. BMJ Qual Saf. 2011;20(3):228-36. https://doi.org/10.1136/bmjgs.2010.043257.

48. Wang Z, Norris SL, Bero L. The advantages and limitations of guideline adaptation frameworks. Implement Sci. 2018;13(1):72. https://doi.org/10.11 86/s13012-018-0763-4.

49. Dizon JM, Machingaidze S, Grimmer K. To adopt, to adapt, or to contextualise? The big question in clinical practice guideline development. BMC Res Notes. 2016;9(1):442. https://doi.org/10.1186/s13104-016-2244-7.

50. Eikermann M, Holzmann N, Siering U, Rüther A. Tools for assessing the content of guidelines are needed to enable their effective use--a systematic comparison. BMC Res Notes. 2014;7(1):853. https://doi.org/10.1186/17560500-7-853.

51. Nuckols TK, Lim YW, Wynn BO, Mattke S, MacLean CH, Harber P, et al. Rigorous development does not ensure that guidelines are acceptable to a panel of knowledgeable providers. J Gen Intern Med. 2008;23(1):37-44. https://doi.org/10.1007/s1 1606-007-0440-9.

\section{Publisher's Note}

Springer Nature remains neutral with regard to jurisdictional claims in published maps and institutional affiliations.

Ready to submit your research? Choose BMC and benefit from:

- fast, convenient online submission

- thorough peer review by experienced researchers in your field

- rapid publication on acceptance

- support for research data, including large and complex data types

- gold Open Access which fosters wider collaboration and increased citations

- maximum visibility for your research: over $100 \mathrm{M}$ website views per year

At BMC, research is always in progress.

Learn more biomedcentral.com/submissions 